\title{
Arterial Assist Intermittent Pneumatic Compression Generating Venous Obstruction with Retrograde Dilatation of Capillaries and Flow Improvement in the Long-Term Therapy of Ischemic Legs
}

\author{
Waldemar Lech Olszewski*
}

Central Clinical Hospital of the Ministry of Interior and Administration in Warsaw, Woloska 137, Warsaw, Mazovian 02507, Poland

\begin{abstract}
Background: Patients with ischemia of lower limbs not suitable for surgical reconstruction of arteries can be treated with assist by intermittent pneumatic compression devices (IPC). Until recently $1-2 \mathrm{sec}$ hit inflation pumps were used generating emptying veins and arterial-venous pressure gradient enabling greater arterial flow. To obtain better perfusion results we used a pump that, in contradiction to the "empty veins" devices, obstructed limb venous outflow by venous occlusions and in a long period therapy expanded perfusion vessels and brought about persistent reactive hyperemia.
\end{abstract}

Aim: To check toe and calf arterial inflow measured by venous stasis plethysmography and capillary flow velocity during arterial assist IPC in a long-term therapy of ischemic legs.

Material and methods: Eighteen patients $(12 \mathrm{M}, 6 \mathrm{~F})$ age 62 to 75 with leg peripheral arterial disease (PAD, Fontaine II) were studied. Pneumatic device with two $10 \mathrm{~cm}$ wide cuffs (foot, calf) (Bio Compression Systems, Moonachie, NJ, USA) inflated to $120 \mathrm{mmHg}$ for 5-6 sec to occlude the venous flow, deflation time $16 \mathrm{sec}$, applied for 45-60 min daily for a period of 2 years.

Results: Increase in toe arterial pressure, volume, capillary blood flow velocity and one-minute arterial inflow test was observed. The two years therapy showed persistence of resting limb increased toe capillary flow. Intermittent claudication distance increased by $20-120 \%$. After two years assist TBI increased from 0.2 to 0.6 (range 0.3 to 0.8 ) ( $\mathrm{p}<0.05$ vs pre-therapy).

Conclusions: The crucial factor of rhythmic repeated venous outflow obstructions should be taken into account in designing effective assist devices.

Keywords: Arteries; Ischemia; Intermittent claudication; Pneumatic compression

\section{INTRODUCTION}

Ischemia of lower limbs due to atherosclerosis of arteries causing intermittent claudication, and in cases of more advanced state necrotic changes of peripheral tissues, concerns in the age group above 60 years between $1 \%$ and $7 \%$ of the population. Pharmacological treatment, especially with statins, limited the indications for surgical treatment, created a challenge for more effective conservative treatment. There is a large group of patients with ischemia of the lower leg and foot without effect of the pharmacological treatment who are not eligible for surgical reconstruction of the arteries due to multi-segmental arterial occlusion and general contraindications for major surgery. The only treatment here is increasing blood peripheral tissue flow with the help of external support by intermittent pneumatic compression devices (IPC) [1]. There is no objective data, except hypotheses from the academic centers, documenting the mechanism of increasing the arterial flow and increasing the knowledge of the beneficial effects [2]. Despite of IPC technology having been available in its present form for many years uncertainty remains about its mechanism to improve arterial inflow and clinical effectiveness in a population who are in urgent need of effective treatment options [3]. Attempts to support the inflow of arterial blood to ischemic limb regions by means of pneumatic pumps and sleeves have a long tradition [4-15].

Correspondence to: Waldemar Lech Olszewski, Central Clinical Hospital of the Ministry of Interior and Administration in Warsaw, Woloska 137, Warsaw, Mazovian 02507, Poland, Tel: 48603865168; E-mail: waldemar.1.olszewski@gmail.com

Received: March 08, 2019; Accepted: April 19, 2019; Published: April 26, 2019

Citation: Olszewski WL (2019) Arterial Assist Intermittent Pneumatic Compression Generating Venous Obstruction with Retrograde Dilatation of Capillaries and Flow Improvement in the Long-Term Therapy of Ischemic Legs. J Vasc Med Surg 7:2. doi: 10.35248/2329-6925.19.7.380

Copyright: (C) 2019 Olszewski WL. This is an open-access article distributed under the terms of the Creative Commons Attribution License, which permits unrestricted use, distribution, and reproduction in any medium, provided the original author and source are credited. 
There are several mechanisms by which a positive effect on the lower limb tissue perfusion is conferred by the use of IPC. These include emptying of the plantar venous plexus, reduction of the venous leg pressure, increase of the arterio-venous pressure gradients in dependent patients, increase of arterial flow, release of vasodilators (nitric oxide, prostacyclins), reduction of local vascular resistance, induction of post occlusive hyperemia and transient suspension of the arteriolar-venous reflex [16-20].

Until recently the generally accepted notion was that by compressing all the tissues below the knee by an inflated cuff, a large volume of venous blood is emptied with venous pressure dropping to nearly zero. The increased arterial-venous pressure gradient results in a greater arterial flow. The applied device pressures were set below arterial pressure so that arterial pressures remained unaffected. The concluding remarks were that "IPC foot-calf is the most effective in emptying the leg veins" [9]. It was reported that using rapid IPC with pressures of around $100 \mathrm{mmHg}$ tripled popliteal artery flow, demonstrating significant decrease in peripheral arterial resistance caused by reduction of venous pressure. It may be presumed that in these studies rapid $0.6 \mathrm{sec}$ inflation of chambers a strike transfer of force generated venous-arteriolar reflex (VAR) with subsequent stop to arterial inflow and vein filling.

The quoted interpretation of the IPC mechanism should be challenged by observation of patients with night pains alleviated by changing supine to sitting leg position increasing venous pressure and volume but not so much arterial limited by atherosclerotic obstruction [21]. It was found that patients with relief of pain while sitting did have a higher capillary density in the sitting position $[22,23]$. Our concept was to follow this observation and apply a slow inflating pump that, due to the IPC long-term repeated venous stasis episodes PC may lead to a persistent dilatation of tissue capillaries. A slow inflation would diminish the venous-arterioral reaction. The retrograde hydrostatic dilatation of microcirculation at the venous end of capillaries will be followed by increase of the capillary exchange surface, slower perfusion, more time for oxygen extraction and absorption of waste products. In this way the arterial flow assist pump limiting venous outflow would mimick the events in veins during changing leg position from the supine to the upright.

In this study we investigated the mechanism of the designed arterial assist pump generating intermittent venous flow obstruction on the toe and calf arterial pulse, toe capillary flow velocity and arterial inflow volume as well as the intermittent claudication distance at two time points, after 1 hour and 2 years daily arterial flow assists.

\section{MATERIAL AND METHODS}

\section{Clinical setting}

Eighteen patients $(12 \mathrm{M}, 6 \mathrm{~F})$ age 62 to 75 with leg peripheral arterial disease (PAD) were studied. Inclusion criteria: patients suffering from leg claudication below $100 \mathrm{~m}$ (Fontaine II), multifocal partial or total obstruction of femoral or calf arteries on arteriography ineligible for surgical revascularization or percutaneous transluminal angioplasty (PTA) due to systemic contraindications. Exclusion criteria: foot inflammation and necrosis, superficial or deep venous thrombosis, the post-thrombotic syndrome, limb posttrauma edema, rheumatic arthritis, previous arterial reconstruction and cardiac arrhythmia. No anticoagulants or vasodilating drugs were taken. The study received consent of the Warsaw Medical University ethics committee.

J Vasc Med Surg, Vol. 7 Iss. 2 No: 380

ISSN: 2329-6925

\section{Pneumatic arterial assist pump}

Pneumatic device with two $10 \mathrm{~cm}$ wide cuffs (foot, calf) (Bio Compression Systems, Moonachie, NJ, USA) slowly inflated to 120 $\mathrm{mmHg}$ for 5-6 sec to occlude the venous flow, deflation time $16 \mathrm{sec}$. Delay between foot and calf inflation was $1 \mathrm{sec}$. Pump was applied daily for 45-60 min for a period of over 2 years. At the initial stage, a two-weeks teaching session was set in our out-patients clinic with instruction on pump use and claudication recording. Intermittent controls were carried out every 3 months. Compliance rates measured by both adherence (to the daily treatment sessions) and persistence (duration of compliance with the course of treatment) were $95 \%$.

\section{Big-toe arterial pressure measurement}

Briefly, a plethysmograph (Hokanson, Bellevue, WA, type EC6) in a recording arterial mode was applied. The sensor was attached to the posterior aspect of the toe.

\section{Continuous point Doppler capillary flow velocity in the big toe and calf skin}

This method was applied to follow changes in the toe and calf skin capillary amplitude (red cell density and movement velocity): a) during arterial assist and b) for measuring arterial closing pressure by gradual venous occlusion at 50, 80, 100 and $120 \mathrm{mmHg}$ before and after each arterial assist cycle. Disappearance of capillary pulse wave was considered as arterial closing pressure. A single-channel laser Doppler flow meter was used with a specialized fiber optic probe to measure blood cell perfusion in the microvasculature of tissues (Relative Red Blood Cell flux) (Figure 1). Class 1 Laser (as per 21 CFR 1040-10 and 1040-11). To obtain the resting capillary flow velocity data the investigated subjects remained in a horizontal position with uncovered limbs, motionless, at room temperature for 15 minutes.

\section{Continuous big toe and calf circumference and volume measurements}

The rate of blood inflow to the big-toe and calf was measured by plethysmography. Briefly, a plethysmograph (Hokanson, Bellevue, WA, type EC6) in a recording vein mode was applied (Figure 1). Mercury strain gauges of a length of $7.5 \mathrm{~cm}$ and $32 \mathrm{~cm}$ were put around the big toe and mid-calf. Elongation of the gauge was read off on the recorder graph scale in $\mathrm{mm}$. It showed increase in circumference brought about by the in-flowing blood. For measuring of arterial inflow (venous volume) a fast 5 seconds

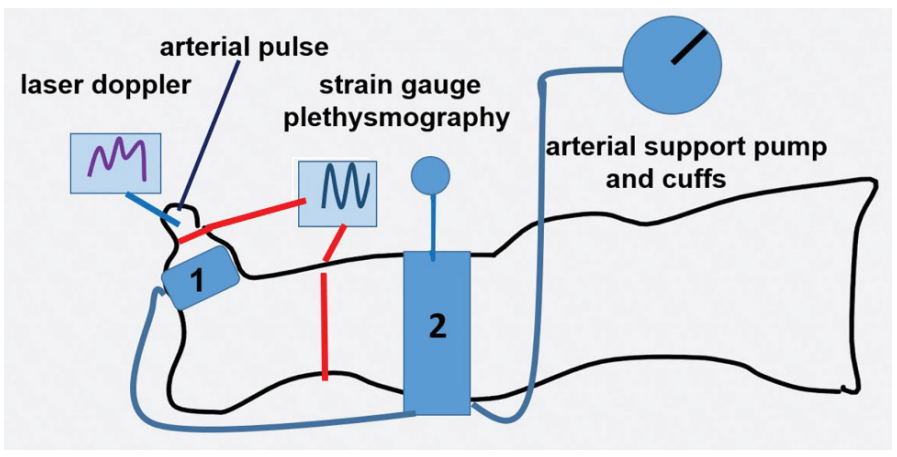

Figure 1: Sites for recording the toe skin capillary flow and arterial pulse, and arterial inflow into toe and calf. Numbers 1 and 2 depict arterial assist pump chambers. 
(filling of large veins) and slow 55 seconds (distension of venous capillaries and plasma filtration) arterial inflow phase curve was recorded. Sequential venous obstruction pressures from 50 to $150 \mathrm{mmHg}$ were used to follow the maximum toe and calf venous (arterial inflow) volume changes. The truncated cone formula for measuring toe and calf volumes changes was applied before and after arterial assist.

\section{Great saphenous vein pressure recording}

Under local anesthesia the 18-gauge needle connected to the pressure transducer (Honeywell, Elblinger, Poland) was introduced to the vein. Recording was done on a device with pressure range from -20 to $+150 \mathrm{mmHg}$ (Telsoft, Warsaw, Poland) and using LabView software (National Instruments, Austin, TX, USA). Position of the transducer was zeroed placing it exactly at the level of the subcutaneously located needle. The data were collected using Microsoft Excel program and were presented graphically on a pressure/time scale.

\section{Statistical evaluation}

Comparison between the pre- and post-therapy data was done using the double-tail Student test with significance at $\mathrm{P}<0.05$.

\section{RESULTS}

The blood flow measurement before and after arterial assist one hour session.

\section{Big-toe arterial pulse}

The pulse amplitude increased immediately after IPC chambers inflation for $5-6 \mathrm{sec}$ by $10-15 \mathrm{mmHg}$, before the inflating pressure reached $120 \mathrm{mmHg}$ bringing about a 2 sec drop of arterial inflow and pressure (Figure 2). This meant that obstruction of the venous outflow produced a few seconds lasting blood accumulation in the veins and in a retrograde fashion the supplying arteries.

\section{Toe and calf skin capillary Doppler recordings}

Toe Doppler capillary red cells flow velocity during single pump inflation: Arterial assist pump inflation was followed by immediate increase in the toe capillary flow velocity in a range from $10 \mathrm{mV}$ to $300 \mathrm{mV}$ depending on the patient, then a slight drop for $2 \mathrm{sec}$ followed by increase to values higher than before pump inflation (Figure 3). Similar recordings were obtained in all patients. Interestingly, in contrast to the toe, calf skin capillary flow did not show evident pre- and post-IPC differences.

Toe capillary Doppler red cell velocity after 10 minutes arterial assist inflations: The pre-assist venous occlusion plethysmography of 50 to $100 \mathrm{mmHg}$ showed decreased capillary flow with occlusion at $120 \mathrm{mmHg}$ in most investigated subjects (Figure 4). The assist pump inflation pressure increased the capillary flow velocity.

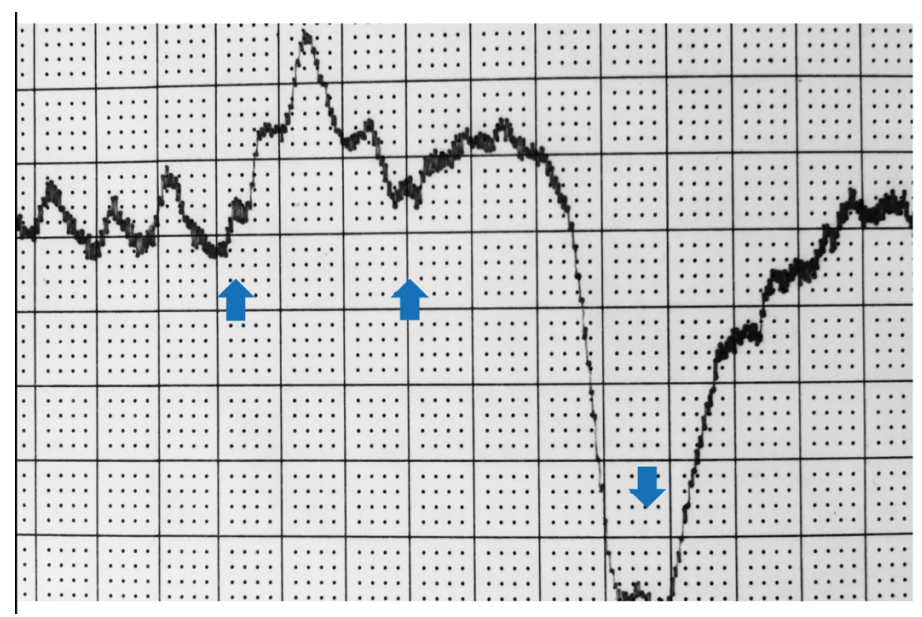

Figure 2: The big toe arterial pulse recording during arterial pump support. First arrow at inflation time of chamber 1 (fore-foot), second of chamber 2 (mid-calf) and third deflation of both chambers. Note increase in pulse amplitude immediately after chambers inflation due to a 4-6 sec toe arterial dilatation, before chamber pressure reaches $120 \mathrm{mmHg}$ causing a 2 sec drop due to stop of arterial inflow.

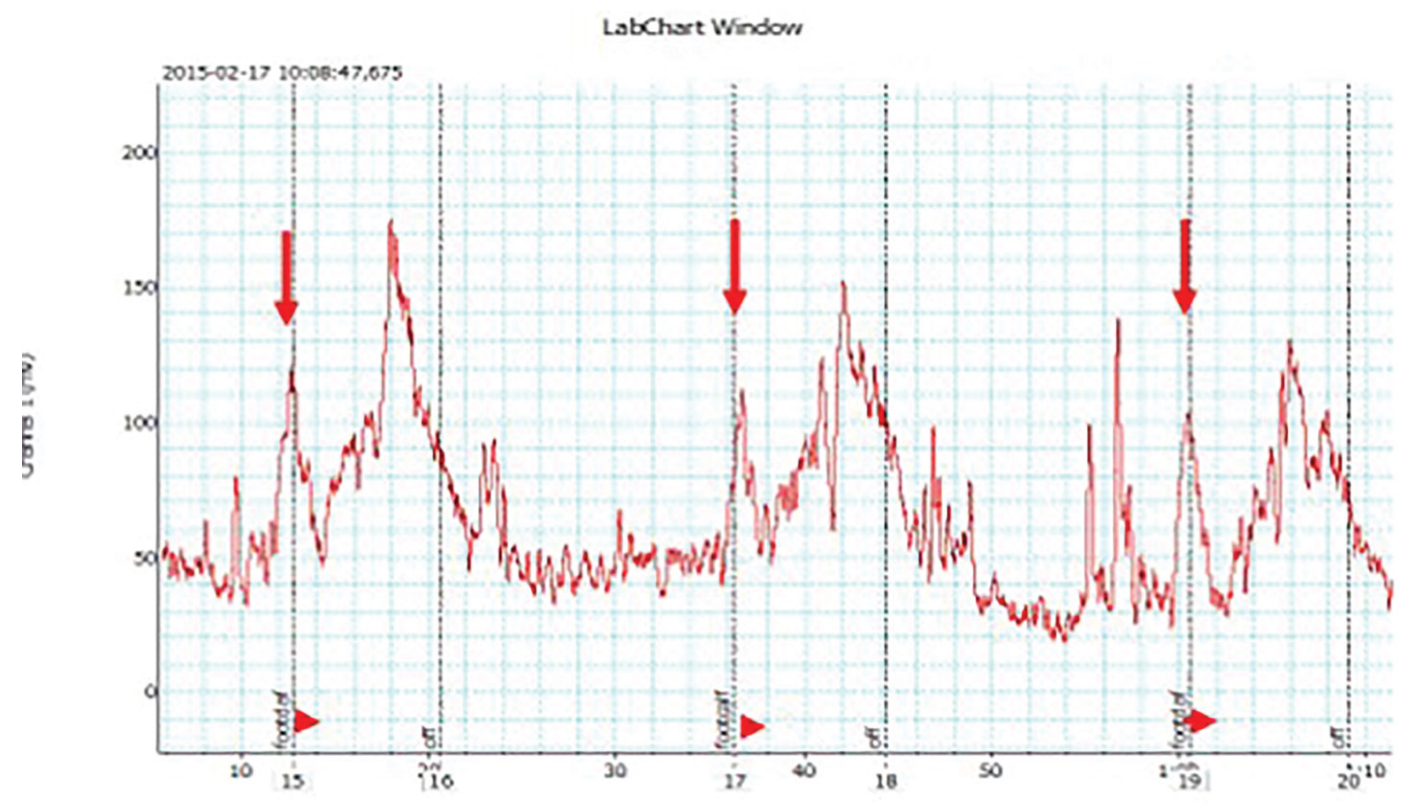

Figure 3: Laser Doppler recording of the big toe capillary flow velocity (in milivolts) during the designed arterial assist pump (arrows point 4-6 sec inflation of foot-calf chambers) in a patient with multifocal calf arteries occlusions. The peak is followed by a short drop and then increase in flow returning to control values during the $16 \mathrm{sec}$ (off) without compression. 
The post-assist plethysmography showed the capillary velocity still present at the occlusion pressure of $120 \mathrm{mmHg}$, recording not seen before he assist. The difference between the pre- and post-IPC was observed in all patients $(p<0.05)$. In some patients plethysmography showed capillary flow after arterial assist even at the occlusion pressure as high as $140 \mathrm{mmHg}$ (Figure 5).

The toe and calf circumference during arterial support: The continuing recording of the toe and calf circumference during inflation of the arterial assist pump showed in all cases an increase, as long as the pump chamber was inflated (Figure 6). This was the effect of temporary accumulation of blood in the most peripheral vessels. At deflation of the arterial pump the circumference returned to the pre-compression values.

The great saphenous vein blood pressure during arterial support: In the 3 investigated subjects there was an increase in pressure (Figure 7). This could be due to stasis of blood in the venous system

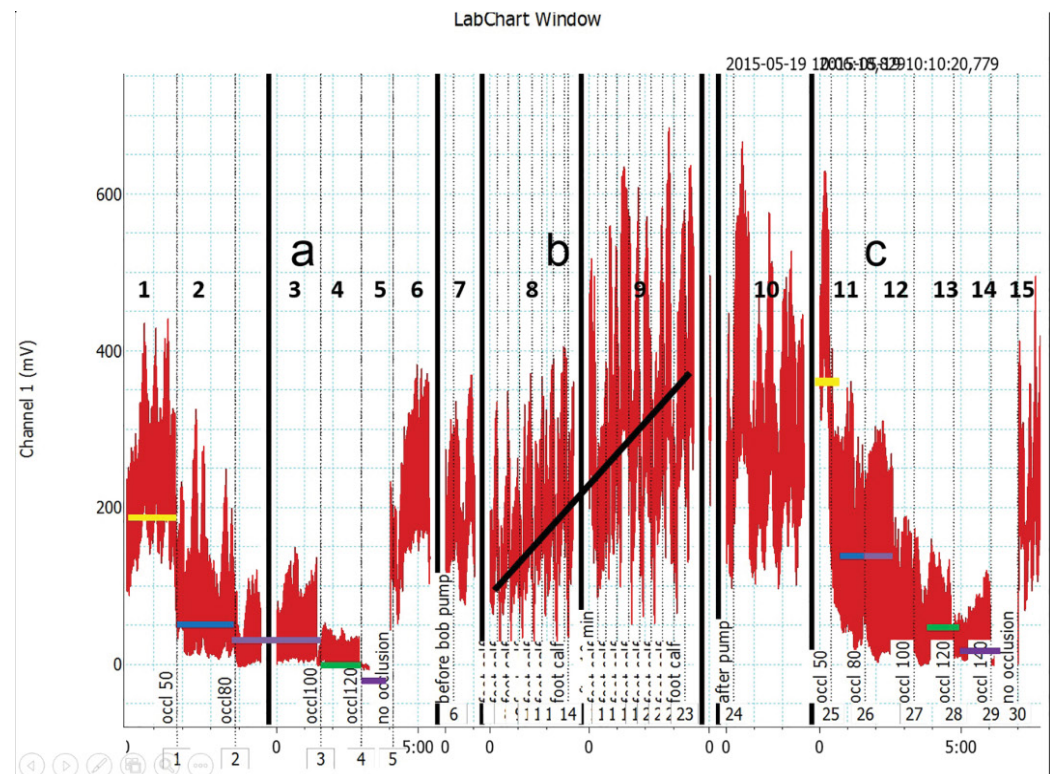

Figure 4: Laser Doppler recording of the big toe capillary flow velocity (in miliVolts) part a) before (points 1-5), no assist (points 6-7), part b) during (points 8-9), no assist (point 10), part c) after (points 11-14), and no assist (point 15) Biocompression arterial pump application in a patient with multifocal calf arteries occlusions. In order to observe the pump effect on the capillary flow before and after IPC the venous occlusion plethysmographic method was used at venous occlusion pressures from 50 through 80,100,120 and $140 \mathrm{mmHg}$, before (points 1-5) and after (points 11-14) 20 arterial pump inflations. Horizontal lines at these points denote mean values. Oblique line in part b point 8 and 9 shows values during pump inflations. Note that capillary flow velocity remained increased after pump assist. Comparison of the pre- and post-IPC capillary flow velocity values showed their higher values after asist even at the plethysmographic arterial inflow occlusion as high as $140 \mathrm{mmHg}$.
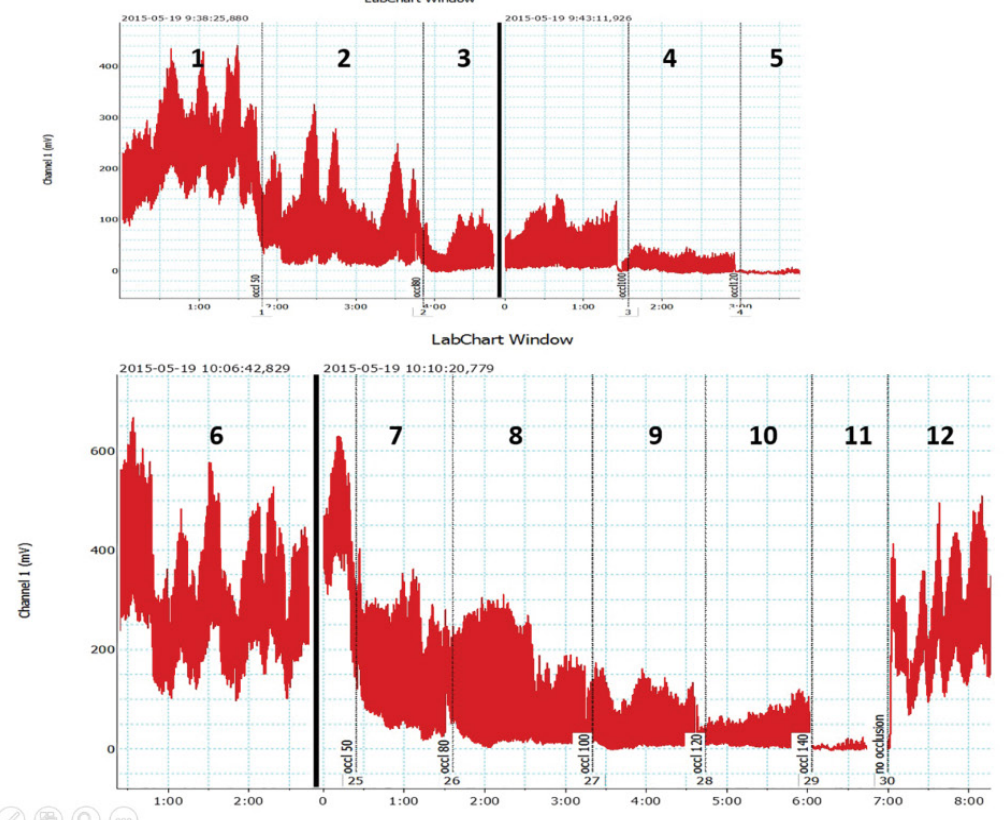

Figure 5: Laser Doppler recording of the big toe capillary flow velocity (in miliVolts) before (upper part) and after (lower part) Biocompression arterial pump assist in a patient with multifocal calf arteries occlusions. Control value (point 1). In order to observe the pump effect on the capillary flow before and after pump assist the venous occlusion plethysmographic method was used at venous occlusion pressures from 50 through $80,100,120$ and 140 $\mathrm{mmHg}$, before (points 2-5) and after (points 7-11) arterial pump inflations. Comparison of the pre- and post-IPC capillary flow velocity values showed higher values after support even at the plethysmographic arterial inflow occlusion of $140 \mathrm{mmHg}$. 
caused by arterial pump venous obstruction. It returned to the initial values at pump cessation.

Plethysmographic measurement of arterial blood inflow before and after arterial assist: One-hour arterial assist evidently increased the toe blood inflow but not so much in the calf (Figure 8). The calculated mean one-minute inflow volume in the calf before IPC at plethysmographic occlusion pressure of $50 \mathrm{mmHg}$ was $25 \mathrm{ml}$ and remained at that level at $120 \mathrm{mmHg}$. In the toe it was $2.5 \mathrm{ml}$ and $0.5 \mathrm{ml}$, respectively. After IPC the calf inflow did not change significantly, whereas, there was an increase in the toe to a mean $6.0 \mathrm{ml}$ at $50 \mathrm{mmHg}$ occlusion and $1.0 \mathrm{ml}$ at $120 \mathrm{mmHg}$.

The blood flow measurement before and after arterial assist for 2 years: Laser Doppler recordings of the big toe capillary flow velocity after 2 years arterial assist in 3 patients are shown on Figures 9 and 10. Evident increased capillary blood velocity in very advanced calf arterial changes as shown on Figure 9 and even in a case of high pre-therapy capillary flow as on Figure 10.

Plethysmographic measurement of arterial blood inflow after 2 years arterial assist: Evidently increased big-toe capillary blood arterial inflow was observed in all cases (Figure 11). The calculated mean one-minute inflow volume in the calf before IPC (day 1) at plethysmographic occlusion pressure of $50 \mathrm{mmHg}$ was $25 \mathrm{ml}$ and remained at that level at $120 \mathrm{mmHg}$. In the toe it was $2.5 \mathrm{ml}$ and $1.5 \mathrm{ml}$, respectively. After IPC (two years) the calf inflow did not change significantly compared to the initial values, whereas, there was an increase in the toe to a mean $6.0 \mathrm{ml}$ at $50 \mathrm{mmHg}$ occlusion

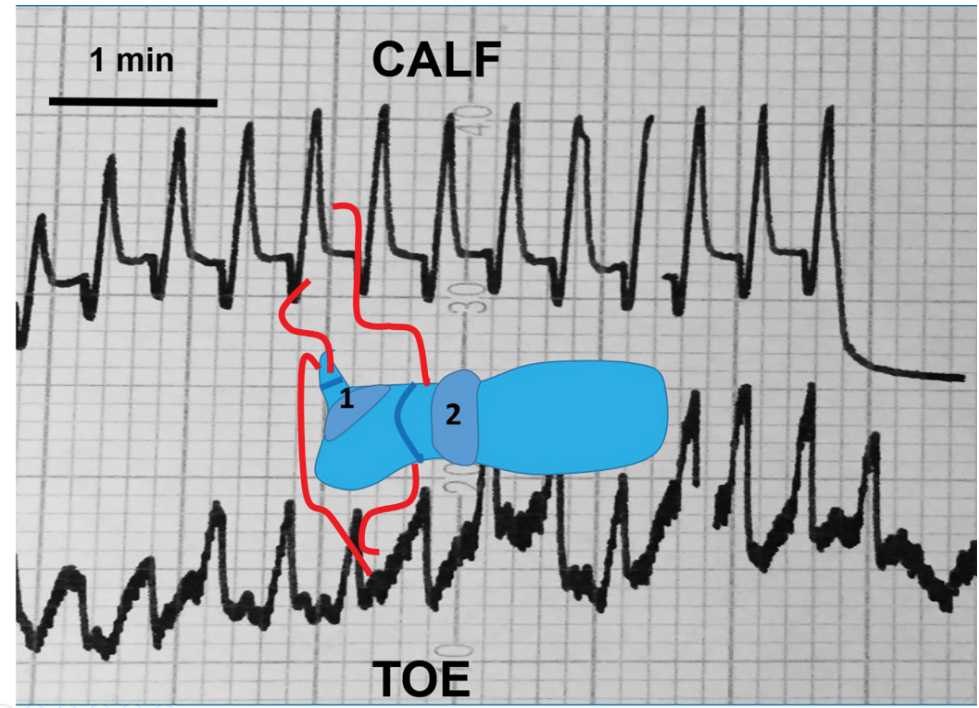

Figure 6: The circumference of the mid-toe and mid-calf was recorded during the arterial assist pump by strain gauge plethysmography in a patient with multifocal calf arteries changes. Number 1 and 2 denote sequentially inflated chambers in front-foot and calf. Blue lines depict strain gauges position. Red lines show time point when inflations began and toe and calf circumferences changed. Elongation of the gauge was read off on the recorder graph scale in $\mathrm{mm}$. Increase in circumference was brought about by the in-flowing blood. Inflation of chamber 1 brought about a 2 sec decrease in calf and increase in toe circumference. Inflation of chamber 2 caused increase of both calf and toe circumference. Deflation was followed by return to the pre-support values. Note that each chamber inflation was followed by increase in toe or calf circumference. This might have been the effect of filling up with blood in occluded toe and calf veins.

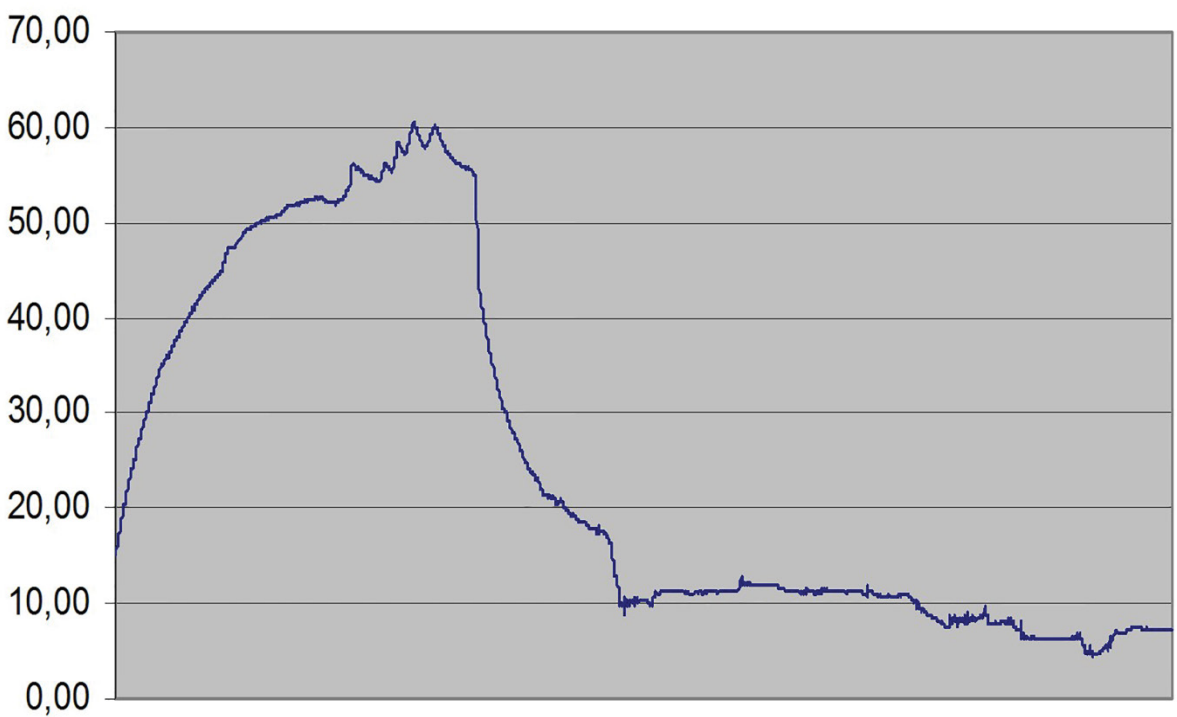

Figure 7: Blood pressure in the great saphenous vein at the ankle level during arterial support pump inflations. Patient in a supine position. Increase of pressure during 10 inflations and fast decrease upon cessation of support. 


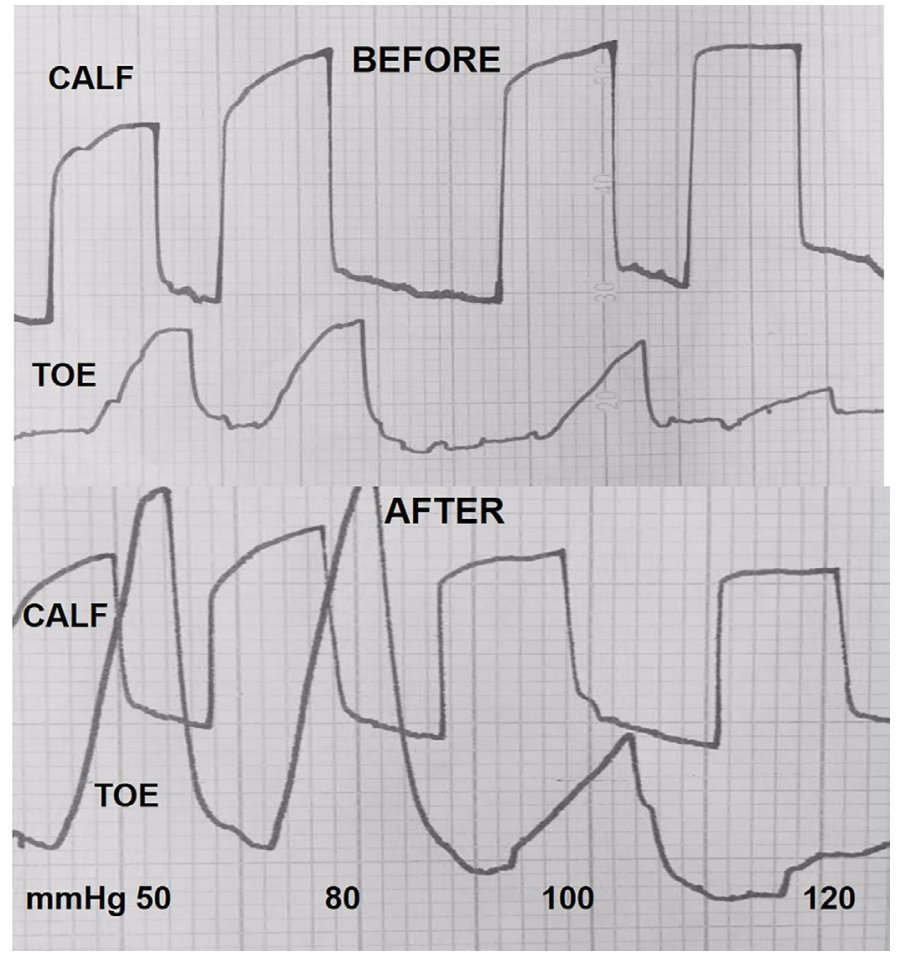

Figure 8: Venous occlusion plethysmography measuring arterial inflow at increasing occlusion pressures in a patient with multifocal changes in the calf arteries. Calf occlusion chamber was inflated to 50 to $120 \mathrm{mmHg}$ pressures before and after 20 compressions of the designed arterial assist pump. Simultaneous recordings in the calf and big toe. Curves show increase of circumferences at each applied $0 \mathrm{mmHg}$ occlusion pressures. Before compression: calf - fast rise of curves reaching same level at occlusion pressures up to $120 \mathrm{mmHg}$, big toe- decreasing peak of circumference at occlusion pressures 100 and $120 \mathrm{mmHg}$. After compression: calf- no evident difference with before arterial assist, big toe- peaks higher than before assist. The difference may be due to the increase in capillary flow.

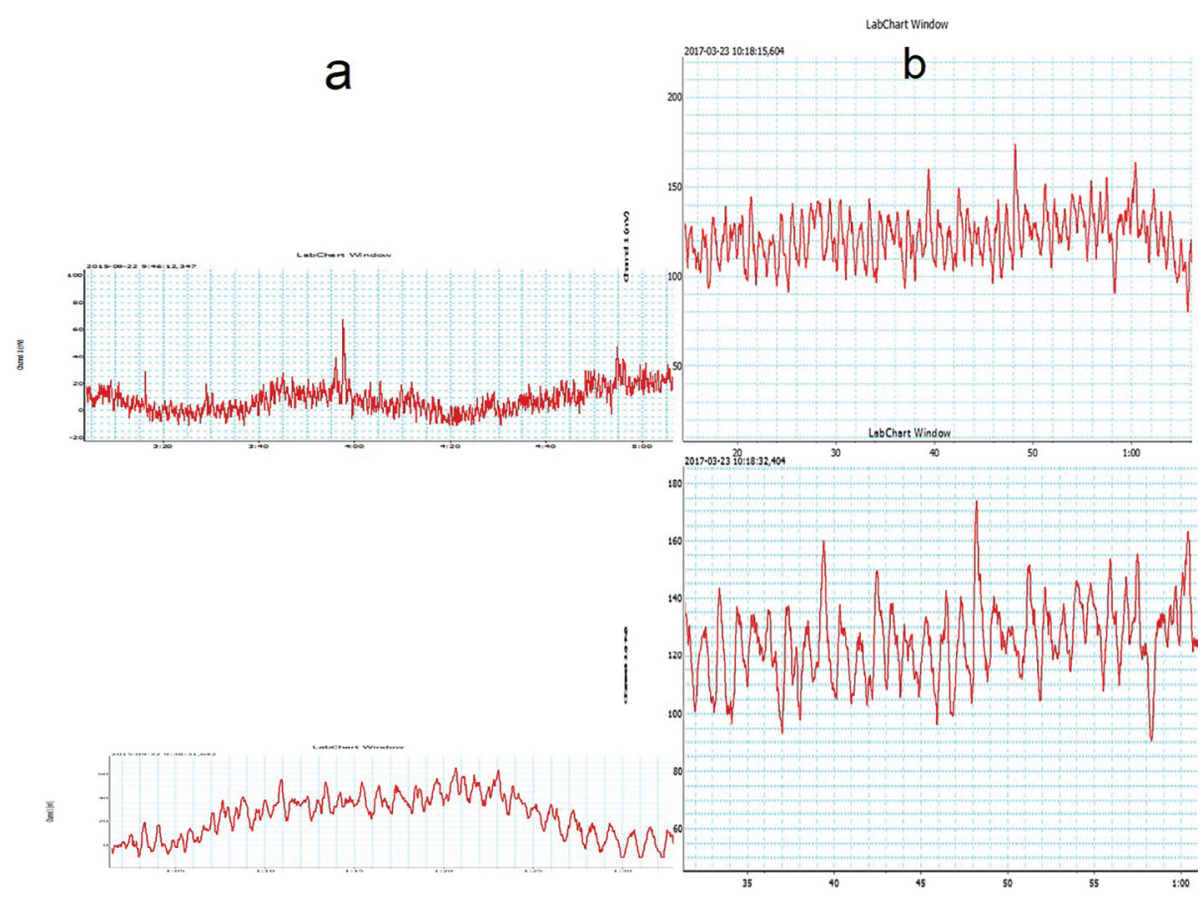

Figure 9: Laser Doppler recording of the big toe capillary flow velocity (in miliVolts) in two patients with multifocal calf arteries occlusions after 2 years of the applied arterial assist. a-before and b-after long-term support. Pre- and post-IPC scales adjusted. Evidently higher amplitudes after long-term therapy.

and $4.0 \mathrm{ml}$ at $120 \mathrm{mmHg}$. Interestingly, even at $150 \mathrm{mmHg}$ occlusion pressure the inflow remained above $3 \mathrm{ml}$.

\section{Clinical evaluation}

Intermittent claudication distance reported by all patients increased by $20-120 \%$. In some cases the distance of $<100 \mathrm{~m}$ increased to over $1000 \mathrm{~m}$. These data were obtained after a 2 years daily arterial support. The mean pretreatment $\mathrm{ABI}$ was 0.64 (range 0.4 to 0.76 ) and 0.7 (range 0.4 to 0.8 ) after one-hour assist (NS). The mean pretreatment TBI was 0.2 (range 0.05 to 0.2 ) and increased to 0.45 (range 0.1 to 0.55$)$ after one-hour assist $(\mathrm{p}<0.05)$. The TBI after two years arterial assist was in the available 6 patients 0.6 (range 0.3 to $0.8)(\mathrm{p}<0.05$ ws pre-therapy). 

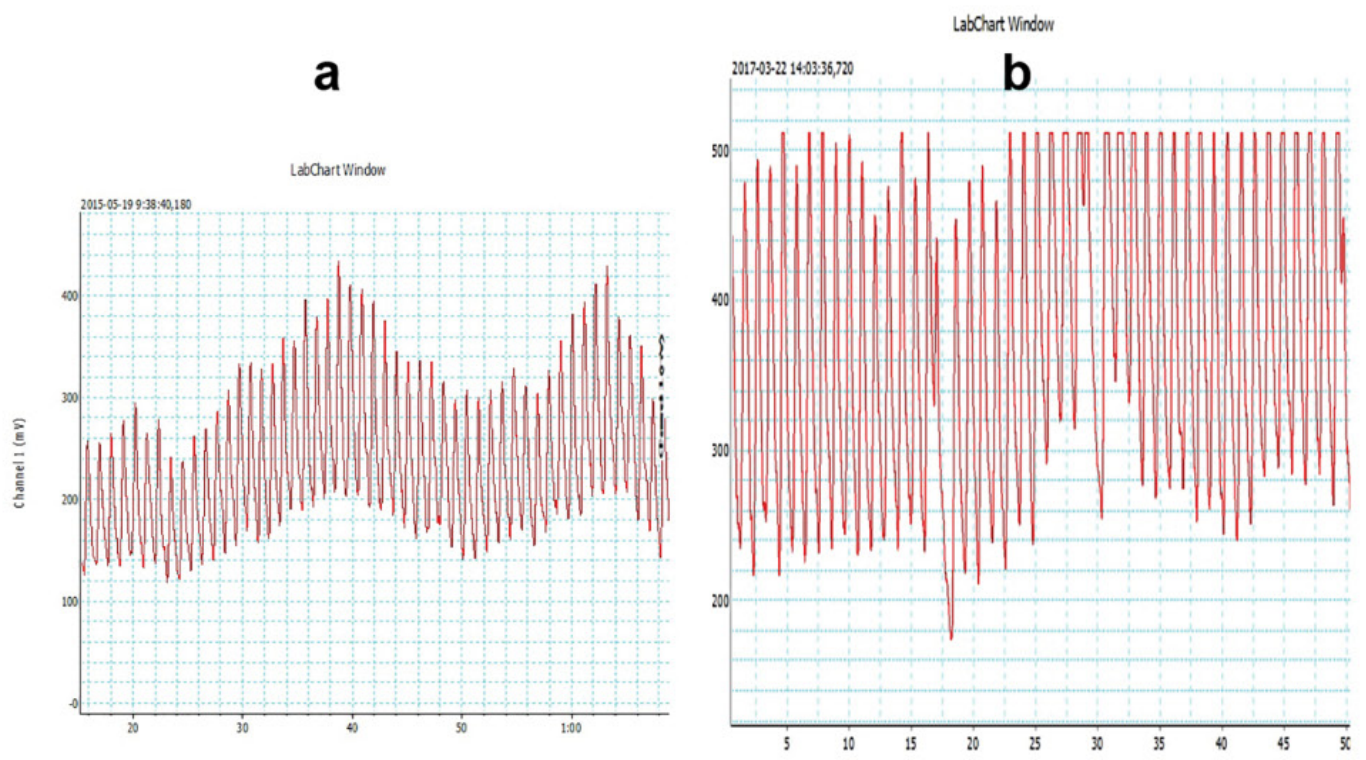

Figure 10: Laser Doppler recording of the big toe capillary flow velocity (in miliVolts) in a patient with occlusion of the superficial femoral artery not suitable for reconstruction after 2 years of the applied arterial assist. a-before and b-after long-term assist. Pre- and post-IPC recording scales adjusted. Although the amplitudes before therapy were high there was an evident increase following the long-term assist.

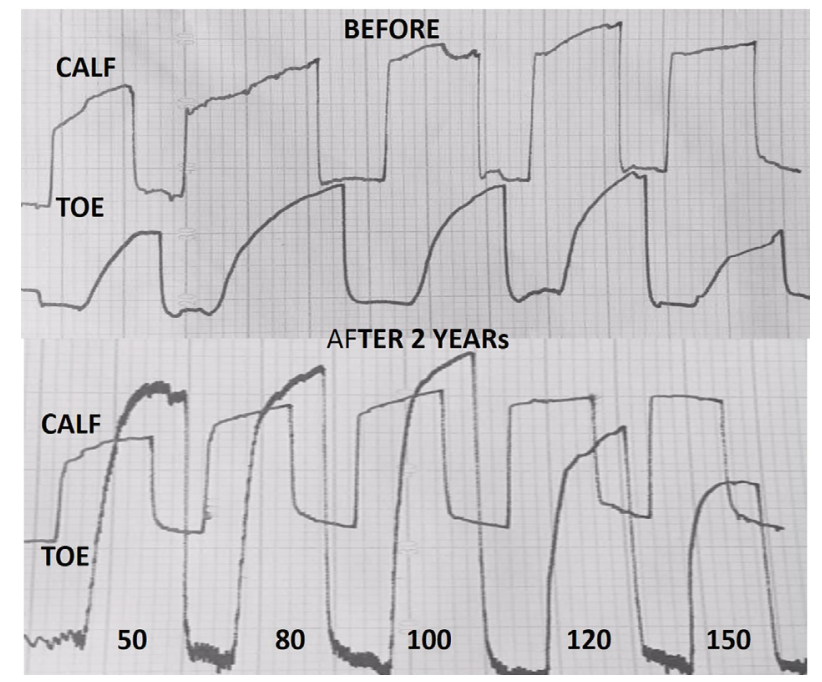

Figure 11: Calf and big toe plethysmography before and after 2 years of daily use of our arterial assist pump in a patient with calf multifocal arterial occlusions. The peak levels of calf arterial inflow do not show major difference before and after therapy. The peak levels of big toe inflow evidently higher than before therapy. Note no stop to capillary flow at venous occlusion pressure of $150 \mathrm{mmHg}$.

\section{DISCUSSION}

Our hypothesis concerning the mechanism of pneumatic arterial support is that obstruction of the limb venous outflow by multiple pump-evoked venous occlusions would in a long period therapy expand the soft tissues network of perfusion vessels, and subsequently bring about persistent reactive hyperemia, restore supply of nutrients and evacuation of waste products. We observed at each of our pump inflation increase in the toe arterial pressure, volume, capillary blood flow velocity and one-minute arterial inflow test. Long-term therapy showed persistence of the increased toe capillary flow velocity and arterial inflow. The TBI increased by approximately $20 \%$. In contrast to the toe, the arterial inflow to the calf skin and muscles did not reveal improvement, however, there was evident prolongation of the claudication distance. The ABI did not increase, however, it may be presumed that dilatation of exchange vessels occurred also in the muscles, although it was not investigated in the present study [12,24].
Our findings concerning the soft tissue hyperemia after pneumatic assist remain in agreement with those of Delvis and Van Bemmelen, however, the interpretation of its mechanism is totally different $[9,25]$. They presumed that emptying of large veins provides space for arterial inflow, whereas we showed evidence of venous blood stasis resulting in persistent retrograde microvasculature dilatation bringing about decreased hydromechanic resistance to the arterial inflow. The difference between our and others' result is that we used a slow inflation pump not evoking the venous-arteriolar reaction stopping the arterial inflow, whereas, they applied the ArtAssist pump striking soft tissues by rapidly inflated chambers for $0.6 \mathrm{sec}$. to $60-140 \mathrm{mmHg}$ bringing about temporary decrease in the arterial flow immediately after this fast inflation due to venousarteriolar reaction. Decreased arterial inflow brought less blood in the veins.

Our arterial assist pump foot and calf chambers were slowly inflated for $5-6 \mathrm{sec}$ to $120 \mathrm{mmHg}$. Inflating first the foot and then the calf chamber increased the toe pulse amplitude in the 
phase of venous outflow obstruction followed by a brief total pulse stop when arteries became occluded. Then, there was a fast restoration of the pulse wave. The increase of pulse amplitude may be accounted for by obstruction of the venous outflow with the still remaining arterial inflow. In concert with the pulse amplitude rise the capillary flow velocity increased for seconds. During the continuing chamber inflations the capillary flow velocity was evidently increasing. Interestingly, it remained high for some minutes after assist cessation. It may be presumed that inflations repeated thousands of times resulted in suppressing the arteriolar vasoconstrictive activity that led to a persistent toe capillary dilatation. The importance of sufficient foot tissue capillary flow was shown by de Graaff who found that in arterial insufficiency of the leg the capillary pressure remains unscathed apparently through arteriolar vasodilation compensating for the low arterial pressure [26].

The consequence of the venous blood pressure hit on the capillary endothelial cells could evoke gene expression effecting the vascular remodeling. The shear stress would be the main mechanical mediator [19]. The response of the endothelial cells resulting in opening more capillaries and their dilatation would be the physiological response to the continuing mechanical stress.

\section{CONCLUSION}

In conclusion, the arterial assist pump we applied in patients with leg ischemia brought about increase in the toe capillary flow, generated long lasting dilatation of toe capillaries and clinically extension of painless walking distance. The physiological effect of arterial assist is dilatation of capillaries by the retrograde force generated by obstruction of venous outflow. Doppler blood velocity test and venous occlusion plethysmography (arterial inflow) of the big toe and calf provided evidence for these hemodynamic effects. The long-term usage of the assist pumps results in persistent dilatation of the microvasculature. The crucial factor of rhythmic multiple venous outflow obstructions causing retrograde capillary dilatation should be taken into account in designing the new effective assist devices.

\section{REFERENCES}

1. Williams KJ, Babber A, Ravikumar R, Davies HK. Non-Invasive Management of Peripheral Arterial Disease. Adv Exp Med Biol - Advances in Internal Medicine. 2016;1:387-406.

2. Chen AH, Frangos SG, Kilaru S, Sumpio BE. Intermittent pneumatic compression devices - physiological mechanisms of action. Eur J Vasc Endovasc Surg. 2001;21(5):383-392.

3. Moran PS, Teljeur C, Harrington P, Ryan M. A systematic review of intermittent pneumatic compression for critical limb ischaemia Vascular Medicine. 2015;20(1):41-50.

4. Bemmelen VPS, Mattos MA, Faught WE, Mansour MA, Barkmeier LD, Hodgson KJ, et al. Augmentation of blood flow in limbs with occlusive arterial disease by intermittent calf compression. J Vasc Surg. 1994;19:1052-1058.

5. Eze AR, Comerota AJ, Cisek PL, Holland BS, Kerr $\mathrm{RP}$, Veeramasuneni $\mathrm{R}$, et al. Intermittent calf and foot compression increases lower extremity blood flow. Am J Surg. 1996;172(2):130-134.

6. Bemmelen VPS, Gitlitz DB, Faruqi RM, Weiss-Olmanni
J, Brunetti VA, Giron F, et al. Limb salvage using highpressure intermittent compression arterial assist device in cases unsuitable for surgical revascularization. Arch Surg. 2001;136(11):1280-1285.

7. Montori VM, Kavros SJ, Walsh EE, Rooke TW. Intermittent compression pump for nonhealing wounds in patients with limb ischemia. The Mayo Clinic experience (1998-2000). Int Angiol. 2002;21(4):360-366.

8. Delis KT, Husmann MJ, Szendro G, Peters NS, Wolfe $\mathrm{JH}$, Mansfield AO. Haemodynamic effect of intermittent pneumatic compression of the leg after infrainguinal arterial bypass grafting. Br J Surg. 2004;91(4):429-434.

9. Delis KT, Nicolaides AN, Labropoulos N, Stansby G. The acute effects of intermittent pneumatic foot versus calf versus simultaneous foot and calf compression on popliteal artery hemodynamics: a comparative study. J Vasc Surg. 2000;32(2):284-292.

10. Delis KT. The case for intermittent pneumatic compression of the lower extremity as a novel treatment in arterial claudication. Perspect Vasc Surg Endovasc Ther. 2005;17:29-42.

11. Husmann M, Willenberg T, Keo HH, Spring S, Kalodiki E, Delis KT. Integrity of venoarteriolar reflex determines level of microvascular skin flow enhancement with intermittent pneumatic compression. J Vasc Surg. 2008;48:1509-1513.

12. Labropoulos N, Leon LR Jr, Bhatti A. Hemodynamic effects of intermittent pneumatic compression in patients with critical limb ischemia. J Vasc Surg. 2005;42:710-716.

13. Ramaswami G, D'Ayala M, Hollier LH, Deutsch R, McElhinney AJ. Rapid foot and calf compression increases walking distance in patients with intermittent claudication: results of a randomized study. J Vasc Surg. 2005;41(5):794-801.

14. Alvarez OM, Wendelken ME, Markowitz L, Comfort C. Effect of High-pressure, Intermittent Pneumatic Compression for the Treatment of Peripheral Arterial Disease and Critical Limb Ischemia in Patients Without a Surgical Option. Wounds. 2015;27(11):293-301.

15. Martin JS, Borges AR, Beck DT. Peripheral conduit and resistance artery function are improved following a single, 1-h bout of peristaltic pulse external pneumatic compression. Eur J Appl Physiol. 2015;115(9):2019-2029.

16. Sutkowska E, Wozniewski M, Gamian A, GoskBierska I, Alexewicz P, Sutkowski K, et al. Intermittent pneumatic compression in stable claudicants: effect on hemostasis and endothelial function. Int Angiol. 2009;28:373-379.

17. Rifkind JM, Nagababu E, Dobrosielski DA, Salgado MT, Lima M, Ouyang P, et al. The effect of intermittent pneumatic compression of legs on the levels of nitric oxide related species in blood and on arterial function in the arm.Nitric Oxide. 2014;40:117-122.

18. Williams KJ, Moore HM, Davies AH. Haemodynamic changes with the use of neuromuscular electrical stimulation compared to intermittent pneumatic compression. Phlebology. 2015;30(5):365-372.

19. Sheldon RD, Roseguini BT, Laughlin MH, Newcomer SC. New insights into the physiologic basis for intermittent pneumatic 
limb compression as a therapeutic strategy for peripheral artery disease. J Vasc Surg. 2013;58:1688-1696.

20. Manfredini F, Malagoni AM, Felisatti M, Mandini S, Lamberti $\mathrm{N}$, Manfredini R, et al. Acute oxygenation changes on ischemic foot of a novel intermittent pneumatic compression device and of an existing sequential device in severe peripheral arterial disease. BMC Cardiovasc Disord. 2014;31:14-40.

21. Ubbink DT, Jacobs JHM, Slaaf DW, Geert J, Tangelder WJM, Reneman RS. Capillary Recruitment and Pain Relief on Leg Dependency in Patients WithSevere Lower Limb Ischemia Circulation. 1992;85:223-229.

22. Kawasaki T, Uemura T, Masumoto K, Harada J, Chuman T, Murat T. The effect of different positions on lower limbs skin perfusion pressure. Indian J Plast Surg. 2013;46(3):508-512.
23. de Graaff JC, Ubbink DT, Lagarde SM, Jacobs MJHM. Postural changes in capillary pressure in the hallux of healthy volunteers. J Appl Physiol. 2003;95(6):2223-2228.

24. Acin F, Florez A, Bleda S, Fernandes LF. A prospective randomized controlled study with intermittent mechanical compression of the calf in patients with claudication. J Vasc Surg 2010;51:857-862.

25. Bemmelen VPS, Weiss-Olmanni J, Ricotta JJ. Rapid intermittent compression increases skin circulation in chronically ischemic legs with infrapopliteal arterial obstruction. Vasa. 2000;29:47-52.

26. de Graaff, Ubbink Th, van der Spruit JA, Lagarde S, Jacobs. Influence of peripheral arterial disease on capillary pressure in the foot. J Vasc Surg. 2003;38:1067-1074. 